\title{
Cognitive leisure activity and all-cause mortality in older adults: a 4-year community-based cohort
}

Xin Liu ${ }^{1,2+}$, Ye Ruan ${ }^{3,4+}$, Limei Huang ${ }^{5}$, Yanfei Guo ${ }^{5}$, Shuangyuan Sun ${ }^{5}$, Hao Chen ${ }^{1,2}$, Junling Gao ${ }^{1,2}$, Yan Shi ${ }^{3,4^{*}}$ and Qianyi Xiao ${ }^{1,2^{*}}$

\begin{abstract}
Background: Cognitive leisure activity, such as reading, playing mahjong or cards and computer use, is common among older adults in China. Previous studies suggest a negative correlation between cognitive leisure activity and cognitive impairment. However, the relationship between cognitive leisure activity and all-cause mortality has rarely been reported.
\end{abstract}

Objectives: This study aims to explore the relationships between cognitive leisure activity and all-cause mortality in a community-based older people cohort in China.

Methods: The current study sample comprised 4003 community residents aged $\geq 60$ y who were enrolled in June 2015, and were followed up every year from 2015 to 2018. Reading, playing mahjong or cards and computer use were measured by questionnaires and summed into a cognitive leisure activity index (CLAl) score. Time-Dependent Cox Regression Model and Kaplan-Meier survival analysis were used to examine the association of cognitive leisure activity with all-cause mortality.

Results: During the 4-year follow-up of 4003 participants, 208 (5.2\%) deaths were registered. Of all participants, 66.8, 26.7, 6.1 and $0.35 \%$ reported CLAl scores of 0, 1, 2 and 3, respectively. A strong association was noted between the CLA score and all-cause mortality (adjusted hazard ratio [HR] $=0.72,95 \%$ confidence intervals [Cl]: 0.54-0.97, $P=$ 0.028). Stratified analysis suggested that a higher CLAl score was significantly associated with a decreased risk of allcause mortality mainly among those who were male, aged $\geq 80 \mathrm{y}$, cognitively impaired, and not diagnosed with cancer $(P<0.05)$.

Conclusion: Cognitive leisure activity was positively associated with reduced risk of death from all cause among the older people in major city of China, which helped promote a comprehensive understanding of health characteristics at advanced ages.

Keywords: Cognitive leisure activity, Mortality, Older adults, Cohort study

\footnotetext{
* Correspondence: Shiyan@scdc.sh.cn; xiaogianyi@fudan.edu.cn

${ }^{+}$Xin Liu and Ye Ruan contributed equally to this work.

${ }^{3}$ Shanghai municipal Center for Disease Control and Prevention, 1380 west

Zhongshan Road, Shanghai 200336, China

${ }^{1}$ School of Public Health, Fudan University, Shanghai 200032, China

Full list of author information is available at the end of the article
}

(c) The Author(s). 2021 Open Access This article is licensed under a Creative Commons Attribution 4.0 International License, which permits use, sharing, adaptation, distribution and reproduction in any medium or format, as long as you give appropriate credit to the original author(s) and the source, provide a link to the Creative Commons licence, and indicate if changes were made. The images or other third party material in this article are included in the article's Creative Commons licence, unless indicated otherwise in a credit line to the material. If material is not included in the article's Creative Commons licence and your intended use is not permitted by statutory regulation or exceeds the permitted use, you will need to obtain permission directly from the copyright holder. To view a copy of this licence, visit http://creativecommons.org/licenses/by/4.0/ The Creative Commons Public Domain Dedication waiver (http://creativecommons.org/publicdomain/zero/1.0/) applies to the data made available in this article, unless otherwise stated in a credit line to the data. 


\section{Background}

The older population has been increasing worldwide, presenting a major challenge to the health and social care system. Chronic diseases are the leading causes of death and disability worldwide [1]. Many studies have implicated lifestyle risk behaviour, such as smoking [2], alcohol use [3] and physical inactivity [4], in adverse health outcomes, including cardiovascular disease, dementia, diabetes, some cancers, and mortality [5]. Hence, substantial disease, mortality, and economic burden could be prevented through modification of lifestyle behaviours [6-8].

Cognitive leisure activity, such as computer use, reading and playing mahjong or cards [9-11], is a type of modifiable lifestyle behaviour and popular in older adults especially retired people in China. In the past few years, the positive association between cognitive leisure activity and good cognitive function has been reported. For example, the computer use was linked to improved cognitive function in older people [12]. Several studies have also identified that reading [9-11, 13, 14], playing board games (mahjong, chess or poker) $[15,16]$, and playing cards $[11,17]$ were associated with a reduced risk of cognitive impairment. It is noteworthy that dementia is one of the most common cognitive-related disorders, ranking as the sixth leading cause of death in the United States and the fifth leading cause of death in Americans aged $\geq 65$ years [18]. It is projected that, by 2050, 1.6 million or $43 \%$ of older adult deaths will be due to dementia and Alzheimer's disease [19]. In addition, accumulating evidence has indicated that leisure activity, including watching TV [20], internet use [21] and reading [22, 23], can make a significant contribution to overall life satisfaction [24-26], which has been identified as an important risk factor for mortality in older people [27-29]. Recently, a prospective cohort study indicated that playing cards or mahjong and reading were association with lower all-cause mortality in the Chinese oldestold population [30]. Another study found an association between daily book reading and survival among men but not women [31]. All these studies compel us to examine whether cognitive leisure activity is associated with allcause mortality, which has rarely been reported.

Using a 4-year prospective cohort study, the present study explores a range of cognitive leisure activities, including reading, playing mahjong or cards, and computer use. The objective of this study was to examine the association between cognitive leisure activity and allcause mortality.

\section{Methods}

\section{Sampling and procedures}

The analyses are based on data from the community physical examination project for the older people, a population-based prospective cohort in Songjiang
District, Shanghai, and the purpose of the original study is to explore the community prevention and intervention of key diseases in the older people. A multi-stage random sampling method was used in this study. This sampling involves a total of 11 streets in Songjiang District. Two streets are randomly selected from the 11 streets, and ten communities were randomly selected from these two streets. Based on the list of Shanghai annual census of registered, 16,809 permanent residents in these ten village communities aged $\geq 60$ years were found at the end of 2014. The project was informed to community residents through community mobilization and the permanent residents aged $\geq 60$ years were invited to participate this project. The Community Neighborhood Committee issued the informed consent to these residents on the list. Participants came to community hospital to participate the investigation and physical examination with the signed informed consent. Finally, a total of 4050 permanent residents aged $\geq 60$ years were recruited for an investigation in the middle of 2015. Baseline data collection was conducted from June 2015 to March 2016. At baseline, demographic and characteristic data, including birth date, gender, height, weight, education years, lifestyles, physical activity (PA), cognitive leisure activity (reading, playing mahjong or cards and computer use), Dementia Screening Interview (AD8) score, medical histories of diabetes, hypertension, coronary heart disease (CHD) and stroke (classified as yes or no), were collected via a face-to-face questionnaire survey by trained personnel. Participants joined the study by completing the questionnaire and the written informed consent form.

\section{Measures}

\section{Mortality}

All-cause mortality and the date of death were ascertained from the Death Surveillance System of Songjiang CDC for all participants after each follow-up, from July 29, 2016 to October 31, 2018. Research coordinators contacted all the participants based on their contact information recorded at the baseline survey and asked for the availability of a clinical interview. Individuals who were deceased were recorded. The date of death was provided by their family members via the telephone call and confirmed by the Death Surveillance System of Songjiang CDC. Those who could not be traced or refused to participate were defined as "lost to follow-up". Participants who missed any of three data points of reading, playing mahjong or cards and computer use at baseline were excluded.

\section{Cognitive leisure activity index construction}

Participants reported on a range of cognitive leisure activities in the questionnaire. Reading status was derived 
from the question "Do you read books or newspapers every day?" Here, "hardly reading" was defined as having no reading habits, whereas "occasionally reading" and "daily reading" were defined as having reading habits. Participants were asked, "Do you often play cards or mahjong?" Among the responses, "almost do not play " was defined as having no habit of playing cards or mahjong, and "several times a month" and "several times a week" were defined as having the habit of playing cards or mahjong. A similar question was also asked, "Do you often use computers to access the internet?" With "Not at all" defined as having no Internet habits, whereas "not every day" and "every day (more than an hour at a time)"were defined as having internet habits.

Considering the inverse association between these three cognitive leisure activities and cognitive impairment [9-17] and mortality [30,31], and their inverse relationship with risk of mortality which is reflected in our study (Supplementary Fig. S1), each cognitive leisure activity was coded as 1 (beneficial) or 0 (not beneficial) and summed as cognitive leisure activity index (CLAI) (total score ranging from 0 to 3 ).

\section{Covariates}

Sociodemographic characteristics were collected from participants' self-reports or physical examinations. Age, sex, BMI (underweight, normal, overweight and obese), education (illiteracy, primary school and $\geq$ junior school), marital status (married and single), and work status (retired, still working, no work) were assessed. BMI was calculated as weight in kilograms divided by height in metres squared. Based on the BMI classification guidelines of the World Health Organization revised for the Asia-Pacific region, we classified the participants into underweight (BMI $\left.<18.5 \mathrm{~kg} / \mathrm{m}^{2}\right)$, normal (BMI: $18.5 \sim$ $22.9 \mathrm{~kg} / \mathrm{m}^{2}$ ), overweight (BMI: $23.0 \sim 29.9 \mathrm{~kg} / \mathrm{m}^{2}$ ) and obese $\left(B M I \geq 30.0 \mathrm{~kg} / \mathrm{m}^{2}\right)$ groups. Smoking status was categorized as current smokers, never smokers, and people who given up smoking. Drinking status was divided into drinking and never drinking. PA was assessed based on self-reports of leisure-time activities, such as fasting walking, playing balls, running, or qigong. (Average physical activity time must exceed 10 min per day.) Participants rated their PA levels as (1) inactive, (2) several times a month, (3) $3-4 \times /$ week, or (4) almost every day. Cognitive assessment was performed according to the AD8 screening questionnaire, participants with AD8 score $\geq 2$ were defined as probably cognitive impairment, whereas AD8 score $<2$ was defined as cognitive normal. In addition, we created a dichotomous variable for cardiovascular or metabolic disease based on the self-report of CHD, stroke, hypertension, and diabetes. Based on the sample distribution, the index of cardiovascular or metabolic disease (CHD, stroke, hypertension, diabetes) was categorized as 0 and 1 (at least one disease). We created an additional dichotomous variable for cancer based on self-report and medical record.

\section{Statistical analysis}

All statistical analyses were performed using SPSS version 22.0 (SPSS, Chicago, IL, USA). Hazard ratios (HRs) and $95 \%$ confidence intervals (CIs) were estimated using Cox Regression Model for the analysis of the association between CLAI and mortality. The Kaplan-meier survival curve for categorical variables and the Schoenfeld residual test for continuous variables were used to check the proportional hazards $(\mathrm{PH})$ assumption prior to running the Cox models. BMI, education attainment, physical activity and smoking status did not satisfy the $\mathrm{PH}$ assumption over time, and were constructed as timedependent covariables. Kaplan-Meier curves were also used to estimate the relationship between CLAI and mortality. The outcome variable was survival time, which was measured as the time interval from the date of baseline data collection to death or censoring. Covariates selected in analyses were based on the criteria of "the variable that is related to the mortality, but not in the causal pathway between most cognitive leisure activities and mortality", and also were referred to relevant literatures [30, 32, 33]. All Time-Dependent Cox Regression Model were adjusted for sex, age (continuous variable), BMI (continuous variable), educational attainment, marital status, work status, smoking status, drinking status, PA, cardiovascular disease, and cancer with covariates classified categorically as per Table 1 . We also examined the independent association of each cognitive leisure activity and all-cause mortality.

Based on the model with the CLAI as the exposure variable, we tested potential effect modification and presented stratified analyses by age group, sex, BMI, educational attainment, PA, cognitive status, whether individuals were diagnosed with cardiovascular or metabolic disease, and whether individuals were diagnosed with cancer. In stratified analyses, age was divided into three groups, including 60-70y, 70-80y, and $80+y$. PA was stratified into a binary variable to intelligibly explain the interaction of PA and cognitive leisure activity on all-cause mortality: physically inactive versus physically active (several times a month, $3-4 \times /$ week, and almost every day). BMI was divided into two groups, including overweight $\left(\mathrm{BMI} \geq 23.0 \mathrm{~kg} / \mathrm{m}^{2}\right)$ and non-overweight $\left(\mathrm{BMI}<23.0 \mathrm{~kg} / \mathrm{m}^{2}\right)$ groups, due to the small sample size in the underweight and obesity groups.

\section{Results}

\section{Descriptive statistics}

Among 4050 participants at baseline, 15 respondents of the final study were lost to follow-up, and 32 participants 
Table 1 Socio-demographic and health characteristics of adults by cognitive leisure activity index score

\begin{tabular}{|c|c|c|c|c|c|c|}
\hline \multirow[t]{2}{*}{ Variable } & \multirow{2}{*}{$\begin{array}{l}\text { Total } \\
n\end{array}$} & \multicolumn{4}{|c|}{ Cognitive leisure activity index score $n$ (Column percentage) } & \multirow[t]{2}{*}{$P$} \\
\hline & & 0 & 1 & 2 & 3 & \\
\hline Total & 4003 & 2674 & 1070 & 245 & 14 & \\
\hline Sex & & & & & & $<0.001$ \\
\hline Male & 1746 & $818(30.6)$ & $708(66.2)$ & $209(85.3)$ & $11(78.6)$ & \\
\hline Female & 2257 & $1856(69.4)$ & $362(33.8)$ & $36(14.7)$ & $3(21.4)$ & \\
\hline Age & & & & & & $<0.001$ \\
\hline $60-70 y$ & 2498 & $1531(57.3)$ & $770(72.0)$ & $185(75.5)$ & $12(85.7)$ & \\
\hline $70-80$ & 1150 & 846 (31.6) & $250(23.4)$ & 53 (21.6) & $1(7.1)$ & \\
\hline$\geq 80 y$ & 355 & $297(11.1)$ & $50(4.7)$ & $7(2.9)$ & $1(7.1)$ & \\
\hline BMI & & & & & & $<0.001$ \\
\hline Underweight & 241 & 177 (6.6) & $51(4.8)$ & $12(4.9)$ & $1(7.1)$ & \\
\hline Normal & 1482 & 1034 (38.7) & 363 (33.9) & $82(33.5)$ & $3(21.4)$ & \\
\hline Overweight & 2084 & 1329 (49.7) & 606 (56.6) & $140(57.1)$ & $9(64.3)$ & \\
\hline Obesity & 196 & $134(5.0)$ & $50(4.7)$ & $11(4.5)$ & $1(7.1)$ & \\
\hline Marital status & & & & & & $<0.001$ \\
\hline Married & 3193 & 2030 (75.9) & 925 (86.5) & 225 (91.8) & 13 (92.9) & \\
\hline Single/ divorced/separated/ widowed/ spinsterhood & 810 & $644(24.1)$ & $145(13.6)$ & $20(8.2)$ & $1(7.1)$ & \\
\hline Educational attainment & & & & & & $<0.001$ \\
\hline Illiteracy & 2260 & $1851(69.2)$ & $384(35.9)$ & $24(9.8)$ & $1(7.1)$ & \\
\hline Primary school & 1181 & $673(25.2)$ & $412(38.5)$ & $94(38.4)$ & $2(14.3)$ & \\
\hline$\geq$ junior school & 562 & $150(5.6)$ & $274(25.6)$ & $127(51.8)$ & $11(78.6)$ & \\
\hline Work status & & & & & & $<0.001$ \\
\hline Retired & 2009 & $1262(47.2)$ & $588(55.0)$ & $148(60.4)$ & $11(78.6)$ & \\
\hline Still working & 627 & $408(15.3)$ & $167(15.6)$ & $50(20.4)$ & $2(14.3)$ & \\
\hline No work & 1367 & $1004(37.5)$ & $315(29.4)$ & $47(19.2)$ & $1(7.1)$ & \\
\hline Physical activity & & & & & & $<0.001$ \\
\hline Inactive & 885 & $617(23.1)$ & $221(20.7)$ & $44(18.0)$ & $3(21.4)$ & \\
\hline Several times a month & 117 & $67(2.5)$ & $41(3.8)$ & $8(3.3)$ & $1(7.1)$ & \\
\hline 3-4x/week & 807 & $574(21.5)$ & $188(17.6)$ & $43(17.6)$ & $2(14.3)$ & \\
\hline Almost every day & 2194 & $1416(53.0)$ & $620(57.9)$ & $150(61.2)$ & $8(57.1)$ & \\
\hline Smoking & & & & & & $<0.001$ \\
\hline Former & 491 & 237 (8.9) & $195(18.2)$ & $57(23.3)$ & $2(14.3)$ & \\
\hline Current & 843 & $344(12.9)$ & $369(34.5)$ & $122(49.8)$ & $8(57.1)$ & \\
\hline Never & 2669 & $2093(78.3)$ & $506(47.3)$ & $66(27.0)$ & $4(28.6)$ & \\
\hline Alcohol use & & & & & & $<0.001$ \\
\hline Drinker & 751 & $312(11.7)$ & $328(30.7)$ & $103(42.0)$ & $8(57.1)$ & \\
\hline Never & 3252 & $2362(88.3)$ & $742(69.3)$ & $142(58.0)$ & $6(42.9)$ & \\
\hline Cardiovascular or metabolic disease & & & & & & 0.047 \\
\hline Physician-diagnosed in past & 2064 & $1345(50.3)$ & $590(55.1)$ & $123(50.2)$ & $6(42.9)$ & \\
\hline Undiagnosed in past & 1939 & $1329(49.7)$ & $480(44.9)$ & $122(49.8)$ & $8(57.1)$ & \\
\hline Cancer & & & & & & 0.860 \\
\hline Physician-diagnosed in past & 87 & $58(2.2)$ & $26(2.4)$ & $3(1.2)$ & $0(0)$ & \\
\hline Undiagnosed in past & 3916 & $2616(97.8)$ & $1044(97.6)$ & $242(98.8)$ & $14(100)$ & \\
\hline Cognitive status & & & & & & $<0.001$ \\
\hline
\end{tabular}


Table 1 Socio-demographic and health characteristics of adults by cognitive leisure activity index score (Continued)

\begin{tabular}{lllllll}
\hline Variable & Total & \multicolumn{4}{l}{ Cognitive leisure activity index score $\boldsymbol{n}$ (Column percentage) } & \multicolumn{2}{c}{$\boldsymbol{P}$} \\
\cline { 5 - 7 } & $\boldsymbol{n}$ & $\mathbf{0}$ & $\mathbf{1}$ & $\mathbf{2}$ & $\mathbf{3}$ \\
\hline Impairment & 250 & $214(8.0)$ & $35(3.3)$ & $1(0.4)$ & $0(0)$ \\
Normal & 3753 & $2460(92.0)$ & $1035(96.7)$ & $244(99.6)$ & $14(100)$ \\
\hline
\end{tabular}

were excluded due to missing CLAI data at baseline. The final sample for analyses included 4003 participants with a mean follow-up of 3.08 (SD 0.39) years, of whom 208 (5.2\%) died prior to October 31, 2018. Table 1 describes the characteristics and the distribution of the final analytical sample. At baseline, the mean age of the participants was $69.37 \pm 7.06$ years (range $60-96$ ). The majority of the participants were female (56.4\%), overweight $(52.1 \%)$, married $(79.8 \%)$, illiteracy $(56.5 \%)$, retired $(50.2 \%)$, physically active almost every day (54.8\%), never smokers (66.7\%), never drinkers $(81.2 \%)$, diagnosed with cardiovascular or metabolic disease (51.6\%), not diagnosed with cancer (97.8\%), and cognitively normal (93.8\%). In addition, we found a greater proportion of illiteracy among women than that among men $(70.6 \%$ vs. $38.2 \%, P<0.001$, Supplementary Table S1), and lower proportion of each cognitive leisure activity (Supplementary Table S1) in women than that in men.

For cognitive leisure activity, $14.9 \%$ of study participants had reading habits, $23.0 \%$ of them played mahjong or cards, and $2.1 \%$ of participants used computers. Overall, $66.8 \%$ of participants reported no cognitive leisure activity (CLAI score $=0$ ), 26.7\% had one cognitive leisure activity, and 6.1 and $0.35 \%$ had CLAI scores of 2 and 3, respectively. Higher CLAI scores were more prevalent among males, those aged 60-70 y, those who were married, those who had a junior school degree or higher, those who were retired, and those who were cognitively normal $(P<0.05$, Table 1$)$.

\section{Individual cognitive leisure activity and all-cause mortality}

When all three dichotomized individual cognitive leisure activities were entered in the model with all covariates, playing mahjong or cards exhibited independent associations with all-cause mortality $(P=0.007$, Supplementary Fig. S1). Reading and computer use also displayed potential beneficial roles in all-cause mortality but with no significant association with all-cause mortality (Supplementary Fig. S1).

\section{Cognitive leisure activity index and all-cause mortality}

Kaplan-Meier survival analysis showed that participants with higher CLAI scores had a significantly decreased

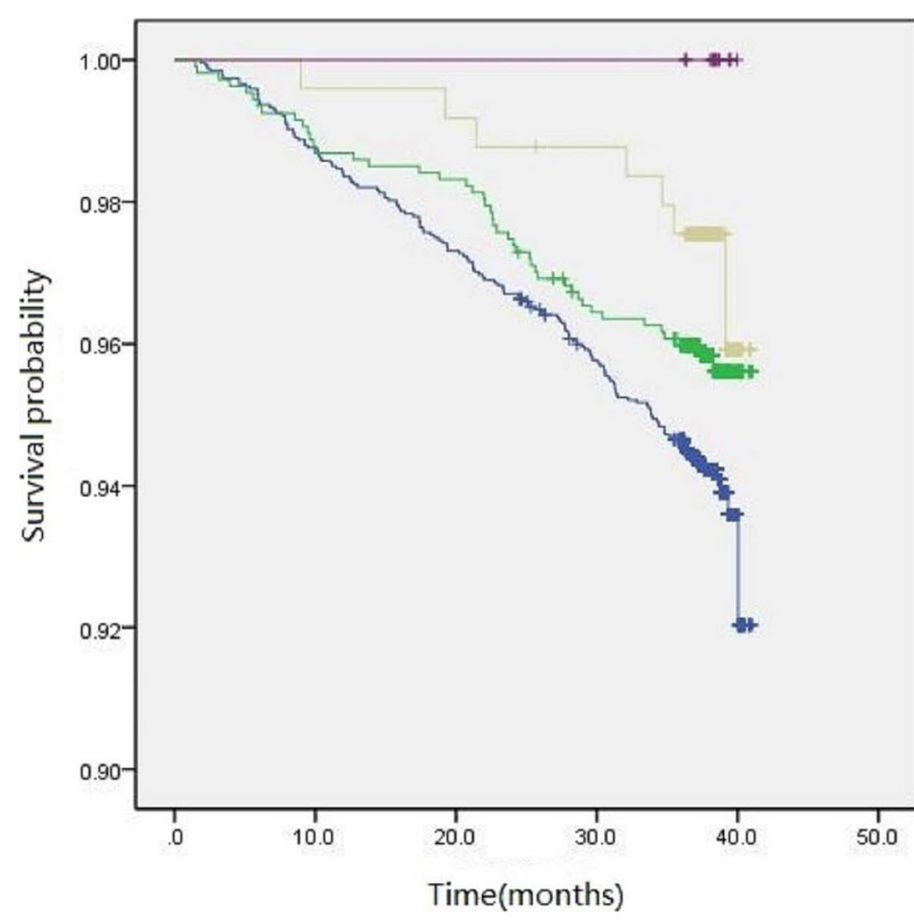

cognitive leisure activity

$\rightarrow 0$

$-2$

+0 -censor

+1 -censor

- 2-censor

+3 - censor

$\mathrm{P}=0.043$

Fig. 1 Kaplan-Meier survival curves of cognitive leisure activity index with survival 
risk of death $(P=0.043$, Fig. 1$)$. Time-Dependent Cox Regression Model also showed an inverse association between the CLAI scores and all-cause mortality (HR = 0.72 , 95\% CI 0.54-0.97, $P=0.028$ ), adjusted for age, sex, BMI, educational attainment, marital status, work status, smoking status, alcohol use status, physical activity, cardiovascular disease, and cancer. (Fig. 2). All-cause mortality HRs compared to individuals without cognitive leisure activity were $0.71(P=0.045)$ and $0.47(P=0.049)$ for those with 1 and 2 cognitive leisure activities in univariate analysis, respectively, whereas these significances were not found in multivariate analysis (Fig. 2).

Stratified analyses suggested an inverse association between CLAI scores and all-cause mortality among participants who were aged $\geq 80$ y $(\mathrm{HR}=0.40,95 \%$ CI 0.20 $0.84, P=0.015)$, those who were male $(\mathrm{HR}=0.67,95 \%$ CI $0.49-0.93, P=0.017)$, those who had cognitive impairment $(\mathrm{HR}=0.08,95 \% \mathrm{CI} 0.01-0.72, P=0.024)$, and those without a cancer diagnosis $(\mathrm{HR}=0.72,95 \% \mathrm{CI}$ $0.53-0.96, P=0.027$ ) (Fig. 3). There was also some indication that CLAI scores were associated with all-cause mortality in participants with PA inactive $(\mathrm{HR}=0.52$, $P=0.014$ in univariate analysis, $\mathrm{HR}=0.60, P=0.068$ in multivariate analysis), who were non-overweight (HR = $0.63, P=0.016$ in univariate analysis, $\mathrm{HR}=0.67, P=$ 0.058 in multivariate analysis) and participant diagnosed with cardiovascular or metabolic disease $(\mathrm{HR}=0.67, P=$ 0.025 in univariate analysis, $\mathrm{HR}=0.69, P=0.060$ in multivariate analysis). Considering the influence of disease status on physical activity, we furtherly analyzed the distribution of cardiovascular or metabolic disease, cancer and BMI between participants with PA active and PA inactive, and found no significant differences (Supplementary Table S2).

\section{Discussion}

This is the first study to our knowledge to investigate an CLAI incorporating reading, playing mahjong or cards and computer use in relation to all-cause mortality. We found that multiple cognitive leisure activities among older Chinese adults were associated with a decreased risk for all-cause mortality over $4 \mathrm{y}$ of follow-up. A clear association was noted between the number of cognitive leisure activities, as indicated by the CLAI score, and allcause mortality.

In the stratified analysis, we identified a significant relationship between cognitive leisure activity and allcause mortality among people with cognitive impairment. Previous evidence indicates the relationship between cognitive leisure activities and cognitive health. $\mathrm{Li}$ and colleagues indicated that reading and computer use were associated with a lower risk of mild cognitive impairment in a population-based study [34]. Lindstrom et al. found an inverse relationship between intellectual activities (reading, playing cards, playing a musical instrument, and letter writing) and Alzheimer's disease or other forms of dementia in a US-based population [17]. Verghese et al. reported that cognitive leisure activities (reading, writing, doing crossword puzzles, playing board games or cards, and playing musical instruments) were associated with a reduced risk of dementia [11]. Despite the heterogeneous measures, risk classification, sample characteristics, and follow-up time of these studies, the association between cognitive leisure activities and cognitive health has been consistent, suggesting the generalizability of these findings. This inverse relationship of cognitive leisure activities with cognitive impairment is further supported here based on our findings, that is, cognitive leisure activity was negatively associated with risk of all-cause mortality in older people. Cognitive impairment has a significant impact on mortality and disability of older population [35]. According to data from the Centers for Disease Control and Prevention (CDC), 121,404 people died from Alzheimer's disease in 2017, and the rate of death from Alzheimer's disease dramatically increased with age, especially after age 65 [18]. Therefore, cognitive leisure activity might influence the risk of mortality partially through the underlying

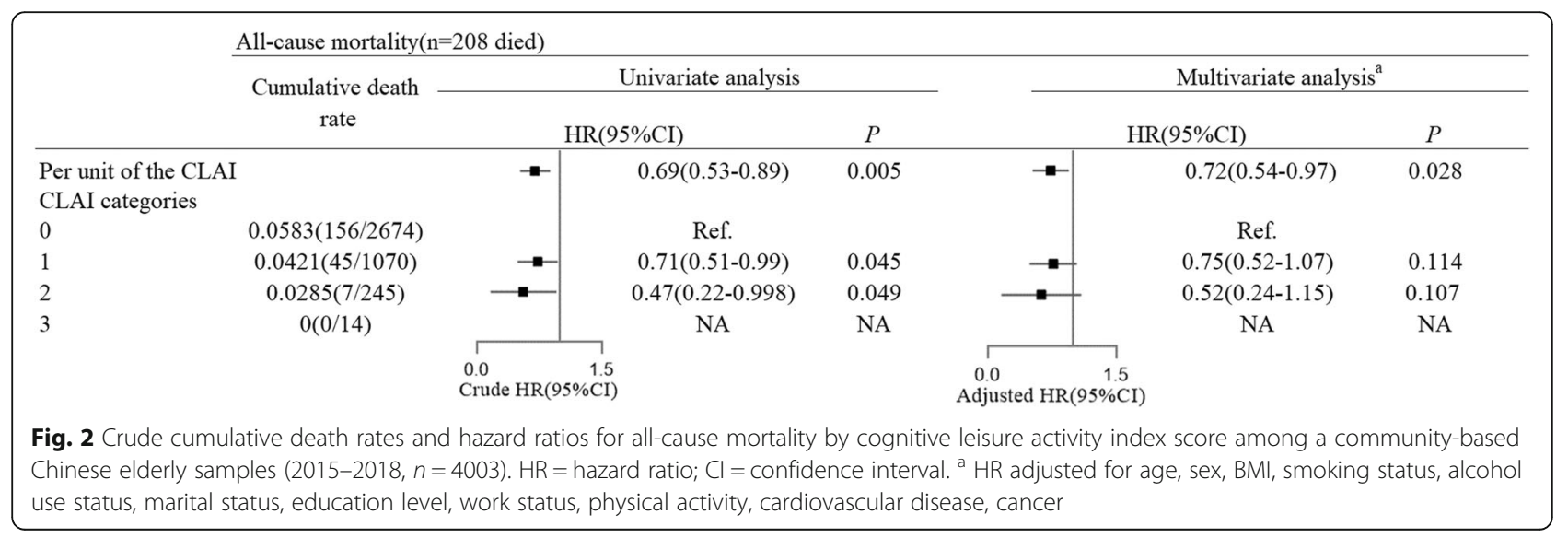




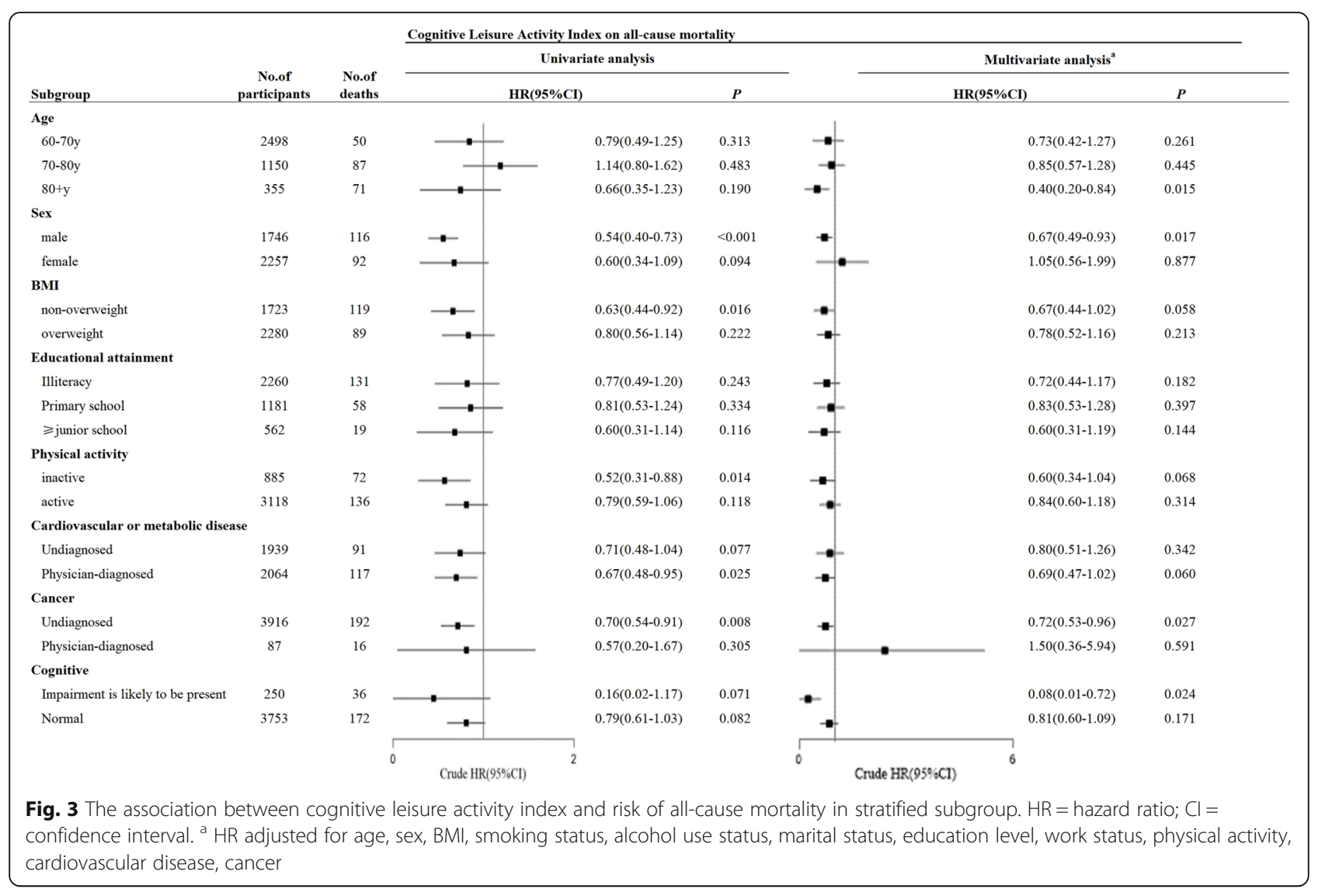

mechanism of its inverse association with cognitive impairment.

It is worth noting that among the three dichotomized individual cognitive leisure activities, playing mahjong or cards exhibited an independent association with allcause mortality. Consistent with our findings, two previous studies reported decreased all-cause mortality among older participants who played cards or mahjong $[30,36]$. One explanation may be that playing mahjong or cards incorporates social engagement. Social engagement, which is defined as the maintenance of many social connections and a high level of participation in social activities, prevents cognitive decline in older persons [37-39]. Additionally, social activities predominantly affect the immune system and influence inflammatory processes in the brain [40, 41]. All these results support our findings that playing mahjong or cards was positively associated with the risk of mortality.

We found a strong association between cognitive leisure activities and all-cause mortality among men not women. Similarly, a previous study has also found an association between daily book reading and longevity among men but not women. Our findings showed a greater proportion of illiteracy among women than that among men $(70.6 \%$ vs. $38.2 \%, P<0.001)$, and a lower proportion of every cognitive leisure activity in women than that in men (Supplementary Table S1). For reading which is depended on knowledge and literacy, men are 4.5 times more likely than women to engage in reading (Supplementary Table S1). Reading and computer use require literacy and the majority of women were illiterate. Therefore, it might be the possible reason why women had lower CLAI scores and showed no association between cognitive leisure activity and mortality.

Stratified analysis indicated a potential relation between cognitive leisure activity and all-cause mortality among participants with physical inactivity in late life $(\mathrm{HR}=0.52, P=0.014$ in univariate analysis, $\mathrm{HR}=0.60$, $P=0.068$ in multivariate analysis, Fig. 3 ), indicating the supplemental role of cognitive leisure activity in healthy living, especially for older people who are unable to perform effective physical activity due to severe chronic disease. Physical activity is a pivotal lifestyle behaviour. Regular physical activity has been irrefutably identified as a protective factor for all-cause mortality [42-44], and the benefit of physical activity was independent of the type of physical activity [45]. Here, our study revealed that the relationship between cognitive leisure activity and all-cause mortality is consistent with that between PA and all-cause mortality in older population. In 
addition, some studies have indicated that cognitive function and physical function influence each other in a feedback loop [46, 47]. An inverse association between physical activity and cognitive impairment has been reported in many studies [48-51], and this association can be attributed to an ameliorated overall health condition [52]. Conversely, cognitive leisure activity is associated with enhanced memory, executive function, language, and cognitive skill [53], which may influence the practice of regular physical activity. For example, execution functions, including volition, planning, purposive action, performance monitoring and inhibition [54], may enable older individuals to consistently engage in physical activity to achieve long-term health benefits [55].

We also found that the CLAI score was associated with lower all-cause mortality among participants without cancer but not among cancer patients. Cancer is a malignant disease in which cognitive leisure activity is not significantly relevant with all-cause mortality, as expected. In fact, many studies have shown the positive relationship between cognitive leisure activity or social activity and quality of life, and the quality of life was reported to have positive association with reduced mortality risk through influencing physical burden, psychosocial burden, and financial burden [56]. This explains why we found a link between the CLAI score and lower all-cause mortality in participants without cancer, and our finding indicated that cognitive leisure activity should be considered in older people's health management. In addition, our results indicated a potential positively association between CLAIs and reduced mortality risk among participants who were diagnosed with cardiovascular or metabolic disease $(\mathrm{HR}=0.67, P=0.025$ in univariate analysis, $\mathrm{HR}=0.69, P=0.060$ in multivariate analysis, Fig. $3)$. Accumulating evidence has indicated that leisure activity, including watching TV [20], internet use [21] and reading [22, 23], can make a significant contribution to overall life satisfaction and psychological well-being $[24,25]$, which is subsequently associated with a lower risk of cardiovascular disease [57, 58]. Thus, a potential pathway by which cognitive leisure activity influences the risk of all-cause mortality might be resulted from reducing the risk of cardiovascular disease or reducing the role of cardiovascular disease on mortality. Although our findings demonstrated the positive association of cognitive leisure activity with allcause mortality based on cohort study and adjusted for cardiovascular or metabolic disease and cancer, there might still be a reverse causality because sicker people might engage in fewer cognitive leisure activities. Cohorts of middle-aged people or randomized controlled clinical trials are justified to test the hypothesis and assess the causality.
Limitations in the current study should be acknowledged. Firstly, it is important to acknowledge that not all three cognitive leisure activities contribute to mortality similarly and that their combined effects may not be additive. However, given the short follow-up period and small sample size, we did not obtain a sufficient prevalence of specific combination patterns of cognitive leisure activities to analyze their associations with all-cause mortality (e.g., prevalence of combination of reading and computer use, combination of playing mahjong or cards and computer use, and combination of both cognitive leisure activities were $1.0 \%(n=41), 0.2 \%(n=9)$ and $0.4 \%(n=14)$, respectively, Supplementary Table S3). Secondly, time spent in each activity was not measured, which may modify the relationship between cognitive leisure activity and mortality. Thirdly, because this study is a secondary analysis of data, we have only investigated three kinds of cognitive leisure activities, which did not represent the full scale of cognitive leisure activities among the older people in China. Future study considering comprehensive cognitive leisure activities needs to be performed to confirm the positive correlation between cognitive leisure activity and reduced risk of mortality. Fourthly, reading and computer use require literacy, whereas $56.5 \%$ of participants in our study were illiterate, which may lead to a lack of applicability of the research conclusion in illiterate populations. Fifthly, this study could be further strengthened by including cause-specific mortality outcomes, but these data are not yet available for the time period studied. Finally, this study assessed older Chinese adults living in a major city, Shanghai, thus potentially limiting the generalizability of our results.

\section{Conclusion}

This study demonstrates the importance of cognitive leisure activity in health lifestyle, here evidenced for adults aged $60 \mathrm{y}$ and older. This analysis investigated three cognitive leisure activities, namely, reading, playing mahjong or cards and using computers, which may be added to behavioural indices or risk combinations to quantify the health risk of older people in China. In addition, our findings advance current knowledge of older people's health and provide a new prevention strategy in older populations in major cities of China.

\section{Abbreviations \\ PA: Physical Activity; CLAl: Cognitive Leisure Activity Index; HR: Hazard Ratio; Cl: Confidence Intervals; BMI: Body Mass Index; SPSS: Statistical Product and Service Solutions}

\section{Supplementary Information}

The online version contains supplementary material available at https://doi. org/10.1186/s12877-021-02180-3.

Additional file1: Figure S1. Kaplan-Meier survival curves of dichotomized individual cognitive leisure activity with survival. (a) playing 
mahjong or cards. (b) reading. (c) computer use. Table S1. The distribution of education level and individual cognitive leisure activity in Men and Women. Table S2. The distribution of cardiovascular disease, cancer and BMI in PA active and PA inactive. Table S3. Prevalence and death rate of all 8 combinations of cognitive leisure activity behaviours.

\section{Acknowledgements}

We gratefully thank all participants and the general practitioners for their cooperation.

\section{Authors' contributions}

Study conception and design: QX. Data collection: YR, LH, YG, and SS. Acquisition, analysis, or interpretation of data: $\mathrm{XL}$ and $\mathrm{YR}$. Statistical analysis: $X L, H C$. Manuscript drafting: XL and QX. Review and comment to manuscript: $J G$ and YS. All authors read and approved the final manuscript.

\section{Funding}

This work was supported by grants from Shanghai Municipal Committee for Health and Family Planning (Grant No. GWV-10.1-XK14). Scientific Research Project from Shanghai Municipal Committee for Health and Family Planning (Grant No. 20174 Y0041 to QX), National Key Research and Development Program of China (Grant No. 2018YFC2002000\&2018YFC2002001) and Program for Outstanding Medical Academic Leader, Shanghai, China (Grant No. 2019LJ24). The funders had no role in the design, methods, subject recruitment, data collection, analysis, or preparation of the paper.

\section{Availability of data and materials}

Datasets used during the current study are available from the corresponding author on reasonable request and with permission of The National Center for Chronic and Noncommunicable Disease Control and Prevention.

\section{Declarations}

\section{Ethics approval and consent to participate}

This study was approved by the Research Ethics Committee of Division for the Prevention and Control of Chronic Noncommunicable Diseases, China Center for Disease Control and Prevention and the Ethics Committee of Department of Public Health in Fudan University, Shanghai, China. All participants or their legally acceptable representatives provided written informed consent.

\section{Consent for publication}

Not applicable.

\section{Competing interests}

The authors declare no conflicts of interest.

\section{Author details}

${ }^{1}$ School of Public Health, Fudan University, Shanghai 200032, China. ${ }^{2}$ Key Lab of Public Health Safety of the Ministry of Education and Key Lab of Health Technology Assessment of the Ministry of Health, School of Public Health, Fudan University, 138 Yixueyuan Road, Shanghai 200032, China. ${ }^{3}$ Shanghai municipal Center for Disease Control and Prevention, 1380 west Zhongshan Road, Shanghai 200336, China. ${ }^{4}$ National Clinical Research Center for aging and Medicine, Huashan Hospital, Fudan University, Shanghai 200040, China. ${ }^{5}$ Songjiang Center of Disease Prevention and Control, Shanghai 201620, China.

\section{Received: 13 July 2020 Accepted: 29 March 2021}

\section{Published online: 09 April 2021}

\section{References}

1. Hamm NC, Pelletier L, Ellison J, Tennenhouse L, Reimer K, Paterson JM, et al. Trends in chronic disease incidence rates from the Canadian chronic disease surveillance system. Health Promot Chronic Dis Prev Can. 2019;39(67):216-24. https://doi.org/10.24095/hpcdp.39.6/7.02.

2. Health UDoe, Services $H$. The health consequences of smoking: a report of the Surgeon General. In: US Department of Health and Human Services, Centers for Disease Control and...; 2004.
3. Corrao G, Bagnardi V, Zambon A, La Vecchia C. A meta-analysis of alcohol consumption and the risk of 15 diseases. Prev Med. 2004;38(5):613-9. https://doi.org/10.1016/j.ypmed.2003.11.027.

4. Lee I-M, Shiroma EJ, Lobelo F, Puska P, Blair SN, Katzmarzyk PT, et al. Effect of physical inactivity on major non-communicable diseases worldwide: an analysis of burden of disease and life expectancy. Lancet. 2012;380(9838): 219-29. https://doi.org/10.1016/50140-6736(12)61031-9.

5. Danaei G, Ding EL, Mozaffarian D, Taylor B, Rehm J, Murray CJ, et al. The preventable causes of death in the United States: comparative risk assessment of dietary, lifestyle, and metabolic risk factors. PLoS Med. 2009; 6(4):e1000058. https://doi.org/10.1371/journal.pmed.1000058.

6. Scarborough $P$, Bhatnagar $P$, Wickramasinghe $K K$, Allender $S$, Foster $C$, Rayner M. The economic burden of ill health due to diet, physical inactivity, smoking, alcohol and obesity in the UK: an update to 2006-07 NHS costs. J Public Health. 2011;33(4):527-35. https://doi.org/10.1093/pubmed/fdr033.

7. Cadilhac DA, Magnus A, Sheppard L, Cumming TB, Pearce DC, Carter R. The societal benefits of reducing six behavioural risk factors: an economic modelling study from Australia. BMC Public Health. 2011;11(1):483. https:// doi.org/10.1186/1471-2458-11-483.

8. Lim SS, Vos T, Flaxman AD, Danaei G, Shibuya K, Adair-Rohani H, et al. A comparative risk assessment of burden of disease and injury attributable to 67 risk factors and risk factor clusters in 21 regions, 1990-2010: a systematic analysis for the global burden of disease study 2010. Lancet. 2012;380(9859): 2224-60. https://doi.org/10.1016/S0140-6736(12)61766-8.

9. Sattler C, Toro P, Schönknecht P, Schröder J. Cognitive activity, education and socioeconomic status as preventive factors for mild cognitive impairment and Alzheimer's disease. Psychiatry Res. 2012;196(1):90-5. https://doi.org/10.1016/j.psychres.2011.11.012.

10. Wilson RS, Scherr PA, Schneider JA, Tang Y, Bennett DA. Relation of cognitive activity to risk of developing Alzheimer disease. Neurology. 2007; 69(20):1911-20. https://doi.org/10.1212/01.wnl.0000271087.67782.cb.

11. Verghese J, Lipton RB, Katz MJ, Hall CB, Derby CA, Kuslansky G, et al. Leisure activities and the risk of dementia in the elderly. N Engl J Med. 2003;348(25): 2508-16. https://doi.org/10.1056/NEJMoa022252

12. Almeida OP, Yeap BB, Alfonso H, Hankey GJ, Flicker L, Norman PE. Older men who use computers have lower risk of dementia. PLoS One. 2012;7(8): e44239. https://doi.org/10.1371/journal.pone.0044239.

13. Iwasa H, Yoshida Y, Kai I, Suzuki T, Kim H, Yoshida H. Leisure activities and cognitive function in elderly community-dwelling individuals in Japan: a 5year prospective cohort study. J Psychosom Res. 2012;72(2):159-64. https:// doi.org/10.1016/j.jpsychores.2011.10.002.

14. Kåreholt I, Lennartsson C, Gatz M, Parker MG. Baseline leisure time activity and cognition more than two decades later. Int J Geriatr Psychiatry. 2011; 26(1):65-74. https://doi.org/10.1002/gps.2490.

15. Paillard-Borg S, Fratiglioni L, Winblad B, Wang HX. Leisure activities in late life in relation to dementia risk: principal component analysis. Dement Geriatr Cogn Disord. 2009;28(2):136-44. https://doi.org/10.1159/000235576.

16. Wang J, Zhou D, Li J, Zhang M, Deng J, Tang M, et al. Leisure activity and risk of cognitive impairment: the Chongqing aging study. Neurology. 2006; 66(6):911-3. https://doi.org/10.1212/01.wnl.0000192165.99963.2a.

17. Lindstrom HA, Fritsch T, Petot G, Smyth KA, Chen $\mathrm{CH}$, Debanne SM, et al. The relationships between television viewing in midlife and the development of Alzheimer's disease in a case-control study. Brain Cogn. 2005;58(2):157-65. https://doi.org/10.1016/j.bandc.2004.09.020.

18. Association As. 2019 Alzheimer's disease facts and figures. Alzheimers Dement. 2019;15(3):321-87. https://doi.org/10.1016/j.jalz.2019.01.010.

19. McAdams-DeMarco MA, Daubresse M, Bae S, Gross AL, Carlson MC, Segev DL. Dementia, Alzheimer's disease, and mortality after hemodialysis initiation. Clin $J$ Am Soc Nephrol. 2018;13(9):1339-47. https://doi.org/10.2215/CJN.10150917.

20. Lee JH, Lee JH, Park SH. Leisure activity participation as predictor of quality of life in Korean urban-dwelling elderly. Occup Ther Int. 2014;21(3):124-32. https://doi.org/10.1002/oti.1371.

21. Khalaila R, Vitman-Schorr A. Internet use, social networks, loneliness, and quality of life among adults aged 50 and older: mediating and moderating effects. Qual Life Res. 2018;27(2):479-89. https://doi.org/10.1007/s11136-01 7-1749-4.

22. Murro V, Sodi A, Giacomelli G, Mucciolo DP, Pennino M, Virgili G, et al. Reading ability and quality of life in Stargardt disease. Eur J Ophthalmol. 2017;27(6):740-5. https://doi.org/10.5301/ejo.5000972.

23. Kaltenegger K, Kuester S, Altpeter-Ott E, Eschweiler GW, Cordey A, Ivanov IV, et al. Effects of home reading training on reading and quality of life in 
AMD-a randomized and controlled study. Graefes Arch Clin Exp Ophthalmol. 2019;257(7):1499-512. https://doi.org/10.1007/s00417-019-0432 8-9.

24. Eifert EK, Hall M, Smith PH, Wideman L. Quality of life as a mediator of leisure activity and perceived health among older women. J Women Aging. 2019:31(3):248-68. https://doi.org/10.1080/08952841.2018.1444937.

25. Badia M, Orgaz MB, Verdugo M, Ullán AM, Martínez M. Relationships between leisure participation and quality of life of people with developmental disabilities. J Appl Res Intellect Disabil. 2013;26(6):533-45 https://doi.org/10.1111/jar.12052.

26. Sener A, Terzioğlu RG, Karabulut E. Life satisfaction and leisure activities during men's retirement: a Turkish sample. Aging Ment Health. 2007;11(1): 30-6. https://doi.org/10.1080/13607860600736349.

27. Lyyra TM, Törmäkangas TM, Read S, Rantanen T, Berg S. Satisfaction with present life predicts survival in octogenarians. J Gerontol B Psychol Sci Soc Sci. 2006;61(6):319-26.

28. Kimm H, Sull JW, Gombojav B, Yi SW, Ohrr H. Life satisfaction and mortality in elderly people: the Kangwha cohort study. BMC Public Health. 2012;12(1): 54. https://doi.org/10.1186/1471-2458-12-54.

29. Collins AL, Glei DA, Goldman N. The role of life satisfaction and depressive symptoms in all-cause mortality. Psychol Aging. 2009;24(3):696-702. https:// doi.org/10.1037/a0016777.

30. Li ZH, Zhang XR, Lv YB, Shen D, Li FR, Zhong WF, et al. Leisure activities and all-cause mortality among the chinese oldest-old population: a prospective community-based cohort study. J Am Med Dir Assoc. 2020;21(6):713-719. e712.

31. Jacobs JM, Hammerman-Rozenberg R, Cohen A, Stessman J. Reading daily predicts reduced mortality among men from a cohort of communitydwelling 70-year-olds. J Gerontol B Psychol Sci Soc Sci. 2008;63(2):S73-80. https://doi.org/10.1093/geronb/63.2.573.

32. Agahi N, Parker MG. Leisure activities and mortality: does gender matter? J Aging Health. 2008;20(7):855-71. https://doi.org/10.1177/0898264308324631.

33. Nilsen C, Agahi N, Shaw BA. Does the association between leisure activities and survival in old age differ by living arrangement? J Epidemiol Community Health. 2018;72(1):1-6. https://doi.org/10.1136/jech-2017-2 09614.

34. Li X, Ma C, Zhang J, Liang Y, Chen Y, Chen K, et al. Beijing ageing brain rejuvenation I: prevalence of and potential risk factors for mild cognitive impairment in community-dwelling residents of Beijing. J Am Geriatr Soc. 2013;61 (12):2111-9. https://doi.org/10.1111/jgs.12552.

35. Liang X, Chen Z, Dong X, Zhao Q, Guo Q, Zheng L, et al. Mental work demands and late-life cognitive impairment: results from the Shanghai aging study. J Aging Health. 2019;31(5):883-98. https://doi.org/10.1177/ 0898264318765034.

36. Sun R, Liu Y. Mortality of the oldest old in China. J Aging Health. 2006;18(1): 37-55. https://doi.org/10.1177/0898264305281103.

37. Bassuk SS, Glass TA, Berkman LF. Social disengagement and incident cognitive decline in community-dwelling elderly persons. Ann Intern Med. 1999;131(3):165-73. https://doi.org/10.7326/0003-4819-131-3-19990803000002.

38. Barnes LL, De Leon CM, Wilson RS, Bienias JL. Evans DA. Social resources and cognitive decline in a population of older African Americans and whites. Neurology. 2004;63(12):2322-6. https://doi.org/10.1212/01.WNL. 0000147473.04043.B3.

39. Newson RS, Kemps EB. General lifestyle activities as a predictor of current cognition and cognitive change in older adults: a cross-sectional and longitudinal examination. J Gerontol Ser B Psychol Sci Soc Sci. 2005;60(3): P113-20. https://doi.org/10.1093/geronb/60.3.P113.

40. Seeman TE. Social ties and health: the benefits of social integration. Ann Epidemiol. 1996;6(5):442-51. https://doi.org/10.1016/51047-2797(96)00095-6.

41. Wang $\mathrm{H}-\mathrm{X}$, Jin $\mathrm{Y}$, Hendrie $\mathrm{HC}$, Liang $\mathrm{C}$, Yang L, Cheng $\mathrm{Y}$, et al. Late life leisure activities and risk of cognitive decline. J Gerontol Series A. 2013;68(2): 205-13. https://doi.org/10.1093/gerona/gls153.

42. Paffenbarger RS Jr, Hyde R, Wing AL. Hsieh C-c: physical activity, all-cause mortality, and longevity of college alumni. N Engl J Med. 1986;314(10):60513. https://doi.org/10.1056/NEJM198603063141003.

43. Kujala UM, Kaprio J, Sarna S, Koskenvuo M. Relationship of leisure-time physical activity and mortality: the Finnish twin cohort. Jama. 1998;279(6): 440-4. https://doi.org/10.1001/jama.279.6.440.

44. Paffenbarger RS Jr, Hyde RT, Wing AL, Lee I-M, Jung DL, Kampert JB. The association of changes in physical-activity level and other lifestyle characteristics with mortality among men. N Engl J Med. 1993;328(8):53845. https://doi.org/10.1056/NEJM199302253280804.

45. Lear SA, Hu W, Rangarajan S, Gasevic D, Leong D, lqbal R, et al. The effect of physical activity on mortality and cardiovascular disease in 130000 people from 17 high-income, middle-income, and low-income countries: the PURE study. Lancet. 2017;390(10113):2643-54. https://doi.org/10.1016/S0140-673 6(17)31634-3.

46. Best JR, Nagamatsu LS, Liu-Ambrose T. Improvements to executive function during exercise training predict maintenance of physical activity over the following year. Front Hum Neurosci. 2014;8:353.

47. Daly M, McMinn D, Allan JL. A bidirectional relationship between physical activity and executive function in older adults. Front Hum Neurosci. 2015;8: 1044.

48. Weuve J, Kang JH, Manson JE, Breteler MM, Ware JH, Grodstein F. Physical activity, including walking, and cognitive function in older women. Jama. 2004;292(12):1454-61. https://doi.org/10.1001/jama.292.12.1454.

49. Laurin D, Verreault R, Lindsay J, MacPherson K, Rockwood K. Physical activity and risk of cognitive impairment and dementia in elderly persons. Arch Neurol. 2001;58(3):498-504. https://doi.org/10.1001/archneur.58.3.498.

50. Yaffe K, Barnes D, Nevitt M, Lui L-Y, Covinsky K. A prospective study of physical activity and cognitive decline in elderly women: women who walk. Arch Intern Med. 2001;161(14):1703-8. https://doi.org/10.1001/archinte.1 61.14.1703.

51. Etgen T, Sander D, Huntgeburth U, Poppert H, Förstl H, Bickel H. Physical activity and incident cognitive impairment in elderly persons: the INVADE study. Arch Intern Med. 2010;170(2):186-93. https://doi.org/10.1001/a rchinternmed.2009.498.

52. Kempermann G, Fabel K, Ehninger D, Babu H, Leal-Galicia P, Garthe A, et al. Why and how physical activity promotes experience-induced brain plasticity. Front Neurosci. 2010;4:189.

53. Wilson RS, Bennett D, Bienias J, De Leon CM, Morris M, Evans D. Cognitive activity and cognitive decline in a biracial community population. Neurology. 2003;61(6):812-6. https://doi.org/10.1212/01.WNL.0000083989.44 027.05.

54. Stuss DT, Levine B. Adult clinical neuropsychology: lessons from studies of the frontal lobes. Annu Rev Psychol. 2002;53(1):401-33. https://doi.org/1 0.1146/annurev psych.53.100901.135220.

55. Hall PA, Fong GT. Temporal self-regulation theory: a model for individual health behavior. Health Psychol Rev. 2007;1 (1):6-52. https://doi.org/10.1 080/17437190701492437.

56. Sitlinger A, Zafar SY. Health-related quality of life: the impact on morbidity and mortality. Surg Oncol Clin N Am. 2018;27(4):675-84. https://doi.org/10.1 016/j.soc.2018.05.008.

57. Kubzansky LD, Huffman JC, Boehm JK, Hernandez R, Kim ES, Koga HK, et al. Positive psychological well-being and cardiovascular disease: JACC health promotion series. J Am Coll Cardiol. 2018;72(12):1382-96. https://doi.org/1 0.1016/j.jacc.2018.07.042.

58. Reavell J, Hopkinson M, Clarkesmith D, Lane DA. Effectiveness of cognitive behavioral therapy for depression and anxiety in patients with cardiovascular disease: a systematic review and meta-analysis. Psychosom Med. 2018;80(8):742-53. https://doi.org/10.1097/PSY.0000000000000626.

\section{Publisher's Note}

Springer Nature remains neutral with regard to jurisdictional claims in published maps and institutional affiliations.

Ready to submit your research? Choose BMC and benefit from:

- fast, convenient online submission

- thorough peer review by experienced researchers in your field

- rapid publication on acceptance

- support for research data, including large and complex data types

- gold Open Access which fosters wider collaboration and increased citations

- maximum visibility for your research: over $100 \mathrm{M}$ website views per year

At $\mathrm{BMC}$, research is always in progress.

Learn more biomedcentral.com/submissions 